\title{
AN INTERMEDIATE HEATING AND COOLING METHOD FOR A DISTILLATION COLUMN
}

\author{
YUJI NAKA, MASAYUKI TERASHITA, \\ SATOSHI HAYASHIGUCHI AND TAKEICHIRO TAKAMATSU \\ Department of Chemical Engineering, Kyoto University, Kyoto 606
}

\begin{abstract}
To save energy in a distillation column, engineers have discussed the application of side-boilers and side-coolers and heat pumps to a distillation column. But no quantitative method which represents the relationship between temperature level and the minimum exchanging heat load of heat source and/or coolant at any plate has been developed. It is very difficult to design a distillation column with such equipment.

This paper represents the energy-saving effects of a side-boiler and a side-cooler on a distillation column on the basis of exergy concepts, and then proposes a quantitative method to determine the feasible domains for the use of a side-boiler and a side-cooler, and to clarify the important relationship mentioned above. This method can be used to design a distillation column with a heat pump and a multi-effective distillation system.
\end{abstract}

\section{Introduction}

Distillation is a unit operation which requires a large amount of energy. To decrease the energy consumption, engineers have tried to apply sideboilers, side-coolers ${ }^{6,8,11,12)}$ and heat pumps ${ }^{3,7,10\}}$ to the distillation column. It might be effective for energysaving to separate a binary mixture by using a heatintegrated multi-column system instead of a single column system ${ }^{2,12,14)}$. Recently, a few distillation systems with such equipment for energy-saving have been realized.

There are different approaches to energy-saving in a distillation system, such as the following: 1) decrease of the summation of heating and/or cooling loads, 2) improvement of the temperature level of available heat sources or coolants, and 3) a combination of both 1) and 2).

This article describes an energy-saving design method for a distillation system which can effectively utilize several kinds of heat source and coolants around a distillation system. Firstly, a theoretical and quantitative consideration of energy-saving by side-boilers and side-coolers is discussed. Secondly, how the feasible domains for the use of side-boilers and side-coolers change according to the variations of feed conditions, specificcations of products, and vapor-liquid equilibrium is studied.

\section{Energy Saving by Using a Side-boiler and a Side- cooler}

This section will consider the advantages of adding

Received August 10, 1979. Correspondence concerning this article should be addressed to $Y$. Naka. side-boilers and side-coolers to a distillation system. The exergy concept based on the first and second laws of thermodynamics is a very powerful means of dealing with both the amount and the quality of heat energy.

Mass and heat balances are given over the conventional column model shown in Fig. 1. It is assumed that the temperature of the tops or the bottoms is equal to the boiling point of each mixture.

(Mass balance)

$$
\begin{gathered}
F=D+W \\
q F x_{F}+(1-q) F Y_{F}=D x_{d}+W x_{w}
\end{gathered}
$$

(Heat balance)

$$
\begin{gathered}
Q_{r}+q F c_{F}\left(T_{F}-T_{\mathrm{o}}\right)+(1-q) F\left[c_{F}^{\prime}\left(T_{F}-T_{\mathrm{o}}\right)+\lambda_{F}\right] \\
=Q_{c}+D c_{d}\left(T_{c}-T_{\mathrm{o}}\right)+W c_{w}\left(T_{r}-T_{\mathrm{o}}\right)
\end{gathered}
$$

where $c_{F}$ and $c_{F}^{\prime}$ mean the specific heat of liquid mixtures with compositions $x_{F}$ and $y_{F}$ respectively.

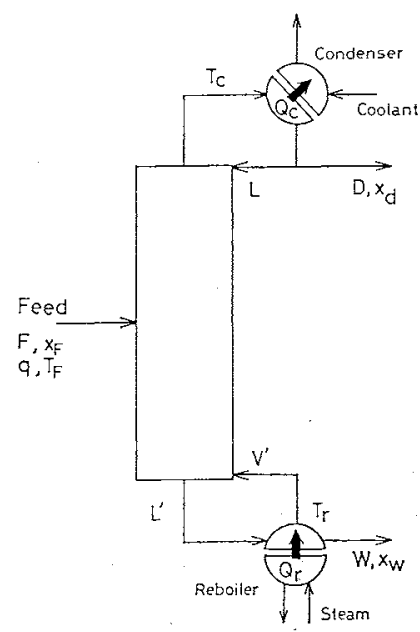

Fig. 1 Conventional distillation column model 


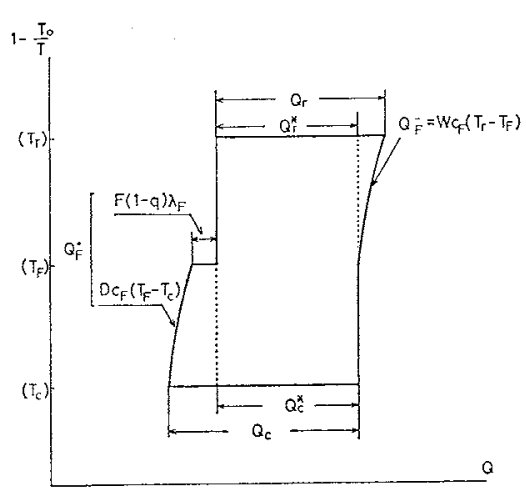

Fig. $2\left(1-T_{0} / T\right)-Q$ diagram of a conventional distillation column

The temperature of the surroundings is expressed by by $T_{0}$. These equations lead to

$$
Q_{r}+Q_{F}^{+}=Q_{c}+Q_{F}^{-}
$$

where

$$
\begin{aligned}
Q_{F}^{+}= & D\left[\left\{q c_{F}+(1-q) c_{F}^{\prime}\right\}\left(T_{F}-T_{\mathrm{o}}\right)-c_{d}\left(T_{\mathrm{o}}-T_{\mathrm{o}}\right)\right] \\
& +(1-q) F \lambda_{F} \\
Q_{F}^{-}= & W\left[c_{w}\left(T_{r}-T_{\mathrm{o}}\right)-\left\{q c_{F}+(1-q) c_{F}^{\prime}\right\}\left(T_{F}-T_{\mathrm{o}}\right)\right]
\end{aligned}
$$

Assuming $c_{F}=c_{F}^{\prime}$, Eqs. (5) and (6) can be written as

$$
\begin{aligned}
& Q_{F}^{+}=D\left[c_{F}\left(T_{F}-T_{\circ}\right)-c_{d}\left(T_{c}-T_{\circ}\right)\right]+(1-q) F \lambda_{F}(7) \\
& Q_{F}^{-}=W\left[c_{w}\left(T_{r}-T_{\mathrm{o}}\right)-c_{F}\left(T_{F}-T_{\circ}\right)\right]
\end{aligned}
$$

The $\left(1-T_{\circ} / T\right)-Q$ diagram for Eq. (4) under the condition of $c_{F}=c_{w}=c_{d}$ is shown in Fig. 2. The supplied heat energies are $Q_{r}$ and $Q_{F}^{+}$and the removed heat energies are $Q_{c}$ and $Q_{\vec{F}}$, in Eq. (4). Defining $Q_{r}^{*}$ and $Q_{c}^{*}$ as

$$
\begin{aligned}
& Q_{r}^{*}=Q_{r}-Q_{F}^{-} \\
& Q_{c}^{*}=Q_{c}-Q_{F}^{+}
\end{aligned}
$$

the following relation is obtained:

$$
Q_{r}^{*}=Q_{c}^{*}=Q^{*}
$$

Then, consider the exergy loss of a distillation column in the surroundings with the temperature, $T_{\mathrm{o}}$, and the pressure, $\pi$, and of the pure nominal state for each component $^{8,9,13}$.

The exergies of a feed, $e_{F}$, the tops, $e_{d}$, and the bottoms, $e_{w}$ are represented as follows:

$$
\begin{aligned}
e_{F}= & F\left[c_{F}\left\{T_{F}-T_{\circ}-T_{\circ} \ln T_{F} / T_{\circ}\right\}+(1-q)\left(1-T_{\circ} / T_{F}\right) \lambda_{F}\right. \\
& \left.+R T_{\circ}\left\{x_{F} \ln x_{F}+\left(1-x_{F}\right) \ln \left(1-x_{F}\right)\right\}\right] \\
e_{d}= & D\left[c_{d}\left\{T_{c}-T_{\circ}-T_{\circ} \ln T_{c} / T_{\circ}\right\}\right. \\
& \left.+R T_{\circ}\left\{x_{d} \ln x_{d}+\left(1-x_{d}\right) \ln \left(1-x_{d}\right)\right\}\right] \\
e_{w}= & W\left[c_{w}\left\{T_{r}-T_{\circ}-T_{\circ} \ln T_{r} / T_{\circ}\right\}\right. \\
& \left.+R T_{c}\left\{x_{w} \ln x_{w}+\left(1-x_{w}\right) \ln \left(1-x_{w}\right)\right\}\right]
\end{aligned}
$$

The values of $e_{F^{\prime}}, e_{d}$ and $e_{w}$ can be evaluated from the conditions of feed and products alone. The exergies of the supplied heat energy and the removed heat energy, $e_{r}$ and $e_{c}$, are given as:

$$
e_{r}=\left(1-T_{\mathrm{o}} / T_{r}\right) Q_{r}
$$

$$
e_{c}=\left(1-T_{\mathrm{o}} / T_{c}\right) Q_{o}
$$

The exergy loss is calculated using Eqs. (12) to (16):

$$
\begin{aligned}
\Delta e_{\mathrm{conv}}= & \left(e_{r}-e_{c}\right)+\left(e_{F}-e_{d}-e_{w}\right) \\
= & T_{\circ}\left[\left(1 / T_{c}-1 / T_{r}\right) Q^{*}+\left(Q_{F}^{+} / T_{\mathrm{c}}-Q_{F}^{-} / T_{r}\right)\right. \\
& \left.-(1-q) F \lambda_{F} / T_{F}\right]+\mathrm{const.} \\
\text { const. }= & R T_{\circ}\left[F\left\{x_{F} \ln x_{F}+\left(1-x_{F}\right) \ln \left(1-x_{F}\right)\right\}\right. \\
& -D\left\{x_{d} \ln x_{d}+\left(1-x_{d}\right) \ln \left(1-x_{i}\right)\right\} \\
& \left.-W\left\{x_{w} \ln x_{w}+\left(1-x_{w}\right) \ln \left(1-x_{w}\right)\right\}\right] \\
& -T_{\circ}\left[F c_{F} \ln T_{F} / T_{\circ}-D c_{d} \ln T_{c} / T_{\circ}\right. \\
& \left.-W c_{w} \ln T_{r} / T_{\circ}\right]
\end{aligned}
$$

The term of $\left(e_{r}-e_{c}\right)$ in Eq. (17) is called "the net work consumption". Since $\left(e_{F}-e_{d}-e_{w}\right)$ can be evaluated only from the design conditions for a column, the exergy loss depends solely on the net work consumption. Moreover, the term "const." can be evaluated from the design conditions. Putting $\Delta e_{\mathrm{conv}}^{\prime}=\Delta e_{\mathrm{conv}}-$ const., $\Delta e_{\mathrm{conv}}^{\prime}$ is equal to the area around the heat availability lines in the $\left(1-T_{\circ} / T\right)-Q$ diagram ${ }^{12)}$ Fig. 2.

Now let us consider the exergy loss for a distillation column with a side-boiler. Denoting the temperature at a heat exchange plate by $T_{j}$ and the heat energy supplied to a side-boiler by $\Delta Q_{r(j)}$, the exergies of the supplied and removed heat energies are given as:

$$
\begin{aligned}
& e_{r}=\left(1-T_{\circ} / T_{r}\right) Q_{r}^{\prime} \\
& e_{j}=\left(1-T_{\circ} / T_{j}\right) \Delta Q_{r(j)} \\
& e_{c}=\left(1-T_{\circ} / T_{c}\right) Q_{c}^{\prime}
\end{aligned}
$$

Where $Q_{r}^{\prime}$ means the heat energy transfered to a reboiler and $Q_{c}^{\prime}$ means the heat energy transfered from a condenser. The heat balance is given by:

$$
Q_{r}^{\prime}+\Delta Q_{r(j)}+Q_{F}^{+}=Q_{c}^{\prime}+Q_{\vec{F}}^{\prime}
$$

and the exergy loss can be written as

$$
\begin{aligned}
\Delta e_{\mathrm{s} 1 \mathrm{de}}= & T_{\mathrm{o}}\left[\left(1 / T_{c}-1 / T_{r}\right) Q^{\prime *}+\left(Q_{F}^{+} / T_{c}-Q_{\bar{F}}^{-} / T_{r}\right)\right. \\
& \left.-(1-q) F \lambda_{F} / T_{F}+\left(1 / T_{r}-1 / T_{j}\right) \Delta Q_{r(j)}\right] \\
& + \text { const. }
\end{aligned}
$$

where

$$
Q^{* *}=Q_{c}^{\prime}-Q_{F}^{+}=Q_{c}^{\prime}+\Delta Q_{r(j)}-Q_{F}^{-}
$$

Consequently, the difference between $\Delta e_{\text {conv }}$ and $\Delta e_{\text {side }}$ becomes:

$$
\begin{aligned}
\Delta e_{\mathrm{coD} \mathrm{V}}-\Delta e_{\mathrm{sid} \mathrm{d}}= & T_{\mathrm{o}}\left[\left(1 / T_{c}-1 / T_{r}\right)\left(Q^{*}-Q^{*}\right)\right. \\
& \left.-\left(1 / T_{r}-1 / T_{j}\right) \Delta Q_{r(j)}\right]
\end{aligned}
$$

As the condition of $Q^{*}=Q^{*}$ is ordinarily satisfied, it becomes:

$$
\Delta e_{\mathrm{conv}}>\Delta e_{\mathrm{side}}
$$

Figure 3 shows $\Delta e_{\text {side }}^{\prime}\left(=\Delta e_{\text {side }}-\right.$ const. $)$.

Similaly, it can be easily determined that the exergy loss of a distillation column with a sidecooler is smaller than that of a conventional column. 
In general, the exergy loss of a distillation column with $m$ side-boilers and $n$ side-coolers is represented as follows:

$$
\begin{aligned}
\Delta e= & T_{\mathrm{o}}\left[\left(1 / T_{c}-1 / T_{r}\right) Q^{*}+\left(Q_{F}^{+} / T_{c}-Q_{F}^{-} / T_{r}\right)\right. \\
& -(1-q) F \lambda_{F} / T_{F}+\sum_{1}^{m}\left(1 / T_{r}-1 / T_{j}\right) \Delta Q_{r(j)} \\
& \left.-\sum_{1}^{n}\left(1 / T_{c}-1 / T_{k}\right) \Delta Q_{c(k)}\right]+\mathrm{const.} \\
Q^{* *}= & Q_{c}^{\prime}+\sum_{1}^{n} \Delta Q_{c(k)}-Q_{F}^{+} \\
= & Q_{r}^{\prime}+\sum_{1}^{m} \Delta Q_{r(j)}-Q_{F}^{-}
\end{aligned}
$$

2. The Relationship between Temperature and Exchanging Energy at the Plate with a Side-boiler or a Side-cooler

Supplying the very large heat energy, $\Delta Q_{r(j)}$, at the $T_{j}$ temperature plate so that reboiler heat requirement, $Q_{r}$, becomes zero, is apparently impossible. In other words, there may be some relationship between $T_{j}$ and the maximum value of $\Delta Q_{r(j)}$. The favorable conditions for the use of side-boilers and side-coolers are discussed in this section.

A conventional column is designed by using the information supplied by the minimum reflux, the minimum number of plates and so on. Assume the heat energies supplied to the reboiler and removed from the condenser under the minimum reflux condition as $Q_{r}^{\min }$ and $Q_{c}^{\mathrm{min}}$, respectively, and the component fraction and the temperature under the 'pinch' condition as $x_{p}$ and $T_{p}$ respectively. The operating line of the stripping section with the reboiler heat requirement, $Q_{r}\left(<Q_{r}^{\mathrm{min}}\right)$ as shown in Fig. $\mathbf{4}$, is given as follows:

$$
\begin{aligned}
y_{j+1}= & \frac{Q_{r}+W\left\{c_{j+1}^{\prime}\left(T_{j+1}-T_{\mathrm{o}}\right)-c_{w}\left(T_{r}-T_{\mathrm{o}}\right)+\lambda_{j+1}\right\}}{Q_{r}-W\left\{c_{j+1}^{\prime}\left(T_{r}-T_{\circ}\right)-c_{j}\left(T_{j}-T_{\mathrm{o}}\right)\right\}} x_{j} \\
& -\frac{W\left\{c_{j+1}^{\prime}\left(T_{j+1}-T_{\mathrm{o}}\right)-c_{j}\left(T_{j}-T_{\circ}\right)+\lambda_{j+1}\right\}}{Q_{c}-W\left\{c_{w}\left(T_{r}-T_{\mathrm{o}}\right)-c_{j}\left(T_{j}-T_{\circ}\right)\right\}} x_{w}
\end{aligned}
$$

In general, $\Delta Q_{r(j)}$ supplied to the $T_{j}$ temperature plate must satisfy the following condition in order to separate a mixture into the specified products:

$$
\Delta Q_{r(j)} \geqq Q_{r}^{\min }-Q_{r}>0
$$

where the equivalence is reached at minimum reflux. The difference between energy losses of the two cases to be supplied at the $T_{j}$ plate and the $T_{j}+\Delta T$ plate on the operating line is obtained by:

$$
\begin{aligned}
& \Delta e_{\text {side }}\left(T_{j}\right)-\Delta e_{\text {side }}\left(T_{j}+\Delta T\right) \\
& \quad=T_{\circ}\left\{1 /\left(T_{j}+\Delta T\right)-1 / T_{j}\right\} \Delta Q_{r(j)}
\end{aligned}
$$

The exergy loss decreases as the heat exchanging plate temperature becomes lower (Fig. 5). On supplying the heat energy, $Q_{r}\left(<Q_{r}^{\mathrm{min}}\right)$, to the reboiler, the lowest heat exchanging temperature, $T_{j}^{*}$, leading to the minimum exergy loss is equal to the temperature at the crossing point between the vapor-liquid equilibrium curve and the operating line given by Eq. (30). This

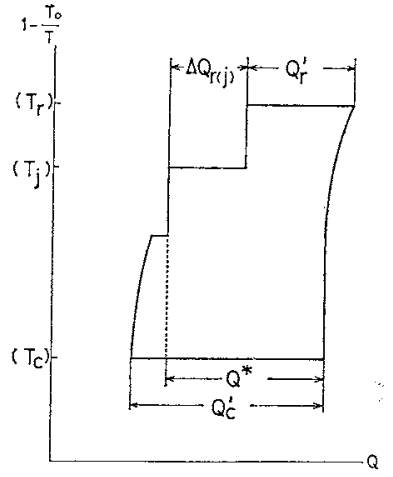

Fig. $3\left(1-T_{0} / T\right)-Q$ diagram of a distillation column with a side-boiler

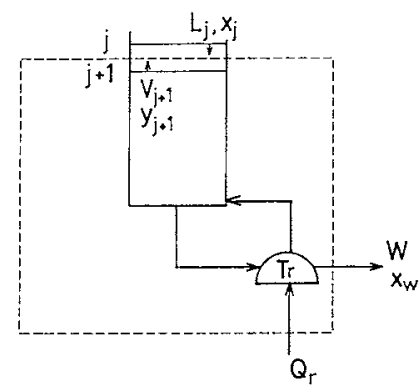

Fig. 4 Stripping section model

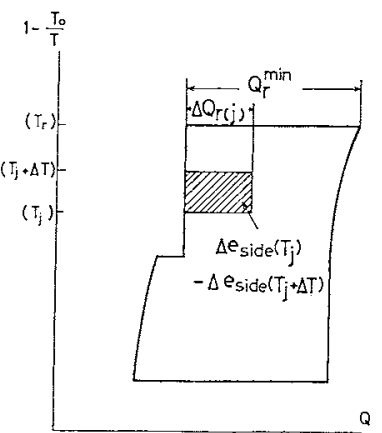

Fig. 5 Exergy loss due to plate temperature difference

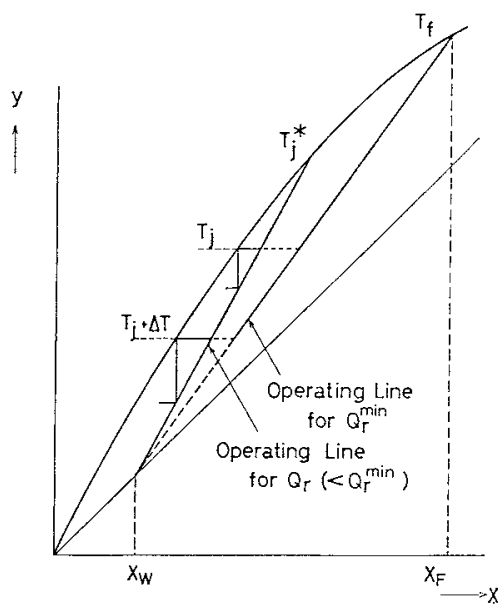

Fig. $6 x-y$ diagram

point is called the pinch point in the case of a sideboiler (Fig. 6). In this case the number of plates is 


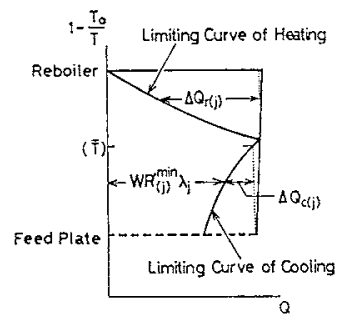

(a) $W R_{(j)}^{\prime \min } \lambda_{j}$ vs. $T_{j}$ (stripping section)

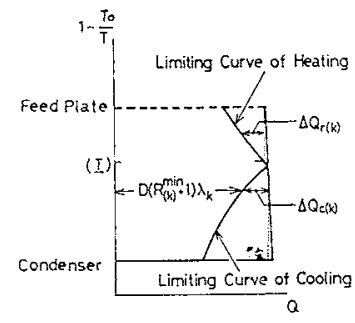

(b) $D\left(R_{(k)}^{\mathrm{min}}+1\right) \lambda_{k}$ vs. $T_{k}$ (enriching section)
Fig. 7

infinite. Consequently, under a given condition of arbitrary heat energy supplied to a reboiler or removed from a condenser, the temperature and the exchanging heat energy at the plate for minimum exergy loss can be determined by the pinch condition mentioned above.

If there is a pinch point at the $k$-th plate of the enriching section, the heat energy removed from a condenser, $Q_{\mathfrak{c}\langle k\rangle}^{\min }$, can be derived from the following equations:

(Mass balance)

$$
\begin{aligned}
& V_{k+1}=L_{k}+D \\
& V_{k+1} y_{k+1}=L_{k} x_{k}+D x_{d}
\end{aligned}
$$

(Heat balance)

$$
\begin{aligned}
& V_{k+1}\left[c_{k+1}^{\prime}\left(T_{k+1}-T_{\mathrm{o}}\right)+\lambda_{k+1}\right] \\
& \quad=L_{k} c_{k}\left(T_{k}-T_{\circ}\right)+D c_{d}\left(T_{c}-T_{\circ}\right)+Q_{c}
\end{aligned}
$$

(Pinch condition)

$$
T_{k+1}=T_{k}, y_{k+1}=y_{k}, \lambda_{k+1}=\lambda_{k}
$$

Therefore

$$
Q_{\mathrm{c}(k)}^{\min }=D\left(R_{(k)}^{\mathrm{m} l \mathrm{n}}+1\right) \lambda_{k}+Q_{(k)}^{+}
$$

where

$$
\begin{aligned}
& R_{(k)}^{\min }=\left(x_{d}-y_{k}\right) /\left(y_{k}-x_{k}\right) \\
& Q_{(k)}^{+}=D\left\{c_{k}\left(T_{k}-T_{\circ}\right)-c_{d}\left(T_{c}-T_{\circ}\right)\right\}
\end{aligned}
$$

$D\left(R_{(k)}^{\min }+1\right) \lambda_{k}$ means the heat energy of the vapor at the $k$-th plate. Assuming the liquid and vapor mole fractions at the pinch point corresponding to the minimum reflux ratio are equal to $x_{p}$ and $y_{p}$, the minimum total removed heat energy becomes:

$$
Q_{c}^{\min }=Q_{c(p)}^{\min }
$$

and the total supplied heat energy is given as follows:

$$
Q_{r}^{\min }=Q_{c}^{\text {min }}-Q_{F^{+}}^{+}+Q_{F}^{-}
$$

On the other hand, if there is a pinch point at the $j$-th plate of the stripping section, the heat energy supplied to a reboiler, $Q_{r(j)}^{\min }$, is derived from the following equations:

(Mass balance)

$$
\begin{aligned}
& L_{j-1}^{\prime}=V_{j-1}^{\prime}-W \\
& L_{j-1}^{\prime} x_{j-1}=V_{j}^{\prime} y_{j}-W x_{w}
\end{aligned}
$$

(Heat balance)

$$
\begin{aligned}
& Q_{r}+L_{j-1}^{\prime} c_{j-1}\left(T_{j-1}-T_{\circ}\right) \\
& \quad=V_{j}^{\prime}\left\{c_{j}^{\prime}\left(T_{j}-T_{\circ}\right)+\lambda_{j}\right\}+W c_{w}\left(T_{r}-T_{\circ}\right)
\end{aligned}
$$

Therefore

$$
Q_{r(j)}^{\min }=W R_{(j)}^{\prime \min } \lambda_{j},+Q_{(j)}^{-}
$$

where

$$
\begin{gathered}
R_{(j)}^{\prime \min }=\left(x_{j}-x_{w}\right) /\left(y_{j}-x_{j}\right) \\
Q_{(j)}^{-}=W\left[c_{w}\left(T_{r}-T_{\mathrm{o}}\right)-c_{j}\left(T_{j}-T_{\mathrm{o}}\right)\right]
\end{gathered}
$$

$W R_{(j)}^{\prime \min } \lambda_{j}$ means the heat energy of the vapor at the $j$-th plate. Assuming the mole fractions of the pinch point for the minimum reflux ratio are equal to $x_{p}$ and $y_{p}$, the minimum total supplied heat energy is given as

$$
Q_{r}^{\min }=Q_{r(p)}^{\min }
$$

and in this case the summation of the removed heat energy can be calculated as follows:

$$
Q_{a}^{\mathrm{min}}=Q_{r}^{\mathrm{min}}-Q_{F}^{-}+Q_{F}^{+}
$$

Changing $x_{j}$ or $x_{k}$ in the regions $x_{w}<x_{j} \leqq x_{f}$ or $x_{f} \leqq x_{k}<x_{d}$, the relationships between the boiling point, $T_{j}$ or $T_{k}$, and the heat duty at a reboiler or a condenser, $Q_{r(j)}^{\min }$ or $Q_{c(k)}^{\min }$, can be obtained. The section in the curve of $W R_{(j)}^{\prime m i n} \lambda_{j}$ vs. $T_{j}$ where $W R_{(j)}^{\min } \lambda_{j}$ increases with decreasing $T_{j}$ is defined as the limiting curve of heating, and the section where $W R_{\langle j\rangle}^{\prime m i x} \lambda_{j}$ decreases is defined as the limiting curve of cooling. These lines are shown in Fig. 7 (a).

Similarly, for the curve of $D\left(R_{(k)}^{\min }+1\right) \lambda_{k}$, the section where $D\left(R_{(k)}^{\mathrm{min}}+1\right) \lambda_{k}$ increases with decreasing $T_{k}$ is defined as the limiting curve of heating and if $D\left(R_{(k)}^{\mathrm{min}}+1\right) \lambda_{k}$ decreases, the section is defined as the limiting curve of cooling. These lines are shown in Fig. 7 (b).

Then, consider the maximum exchanging heat energy at the $T_{j}$ temperature plate for a distillation system with a set of limiting curves of heating and cooling. (See example No. 4 in the case except for the system mentioned above.) Under the given value of the total heat energy requirements, $Q_{r}^{\mathrm{min}}, \Delta Q_{r(j)}$ supplied to the $T_{j}$ plate on the limiting curve of heating can be easily obtained as follows: $T$ denotes the limited temperature of using a side boiler. (See Appendix)

i) in the stripping section:

$$
\Delta Q_{r(j)}=Q_{r}^{\min }-Q_{r(j)}^{\min }
$$

ii) in the enriching section:

$$
\Delta Q_{r(k)}=Q^{* \min }-D\left(R_{(k)}^{\min }+1\right) \lambda_{k}\left(T_{F} \geqq T_{k e}>\underline{T}\right)
$$

$\Delta Q_{r(j)}$ and $\Delta Q_{r(k)}$ are shown in Fig. 7 (a) and (b). Analogously, if the total removed heat energy, $Q_{c}^{\text {min }}$, is fixed, the maximum heat energy removed from the $T_{j}$ temperature plate on the limiting curve of cooling can be derived as follows: $\bar{T}$ denotes the limited temperature of using a side cooler. (See Appendix.)

i) in the stripping section:

$$
\Delta Q_{c(j)}=Q^{* \text { min }}-W R^{\prime(j)} \underset{(j)}{\prime m i n} \lambda_{j}\left(\bar{T}>T_{j} \geqq T_{F}\right)
$$




\begin{tabular}{lcccc}
\hline \multicolumn{4}{c}{ Table 1 } & \multicolumn{4}{c}{ Design conditions of examples } \\
Example & \multicolumn{1}{c}{1} & 2 & 3 & 4 \\
& Benzene-Toluene & \multicolumn{3}{c}{ Ethanol-Acetic } \\
\hline Feed rate $F[\mathrm{~kg}-\mathrm{mol} / \mathrm{hr}]$ & 50.0 & 50.0 & 50.0 & 50.0 \\
Frac. $x_{\mathrm{F}}[\mathrm{mol} \%]$ & 60.0 & 60.0 & 18.2 & 40. \\
$q$-value & 1.0 & 0.0 & 1.0 & 1.0 \\
Distillate $x_{d}[\mathrm{~mol} \%]$ & 95. & 95. & 99. & 99.0 \\
\hline Bottoms $x_{w}[\mathrm{~mol} \%]$ & 5.0 & 5.0 & 1.0 & 1.0 \\
\hline Heat capacity (liquid) & Reference 13) & & \\
Latent heat & Reference 13) & \\
V-L equi. & Reference 14) \\
\hline
\end{tabular}

ii) in the enriching section:

$$
\Delta Q_{c(k)}=Q_{c}^{* \text { min }}-Q_{c(k)}^{\min }
$$

$\Delta Q_{c(j)}$ and $\Delta Q_{c(k)}$ are shown in Fig. 7 (a) and (b). (Example No. 1) Benzene-toluene distillation column

The feed conditions and the specifications of the products are given on Table 1. In this example the pinch point for the minimum reflux ratio is at the feed plate. The calculated values from Eqs. (4), (37) and (45) are shown in Fig. 8. (As the exergy loss will be not directly discussed below, $\left(1-T_{0} / T\right)-Q$ diagram is substituted for $T-Q$ diagram.) The location of $Q^{+}$is different from that in Fig. 2 in order to present the maximum exchanging heat energies, $\Delta Q_{r(j)}$ and $\Delta Q_{c(k)}$, at the $T_{j}$ and $T_{k}$ temperature plates. The $a b$ curve is the limiting curve of heating. The shadow area bounded by ab, $Q_{r}^{\min }$ and $Q_{F}^{-}$indicates the feasible domain to add side-boilers. On the other hand, the curve of bc is the limiting curve of cooling and it is possible to equip side-coolers in the shadow area bounded by ab, $Q_{c}^{\text {min }}$ and $Q_{F}^{+}$.

(Example No. 2) Benzene-toluene distillation column

The design conditions of this example, except for $q=0$, are the same values as in example No. 1 . The curves of abd and be shown in Fig. 9 agree with the curves of $a b$ and $b c$ for example No. 1 .

(Example No. 3) Ethanol-acetic acid distillation column

The pinch point for the minimum reflux ratio is in the stripping section. The curves of $a b$ and bcd shown in Fig. 10 are the limiting curves of heating and cooling respectively. It is possible to add side-coolers not only in the enriching section but also in the part of the stripping section in order to recover high-temperature waste heat energies.

(Example No. 4) Ethanol-acetic acid distillation column

The limiting curves under the given design conditions are shown as $a b$, cd for heating and $b c$, df for cooling in Fig. 11. There is a switching point between cooling and heating operations in the stripping section. Since $W R^{\prime \min } \lambda_{p}$ under the minimum reflux ratio is larger than $Q^{*}$, the maximum removed heat energy in the

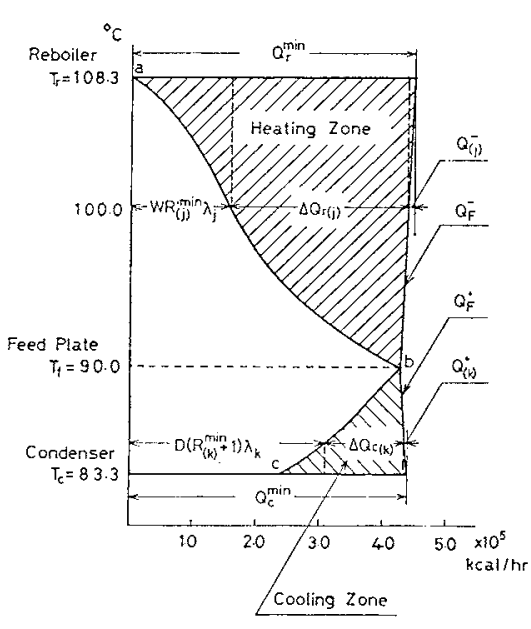

Fig. $8 T-Q$ diagram of Example No. 1

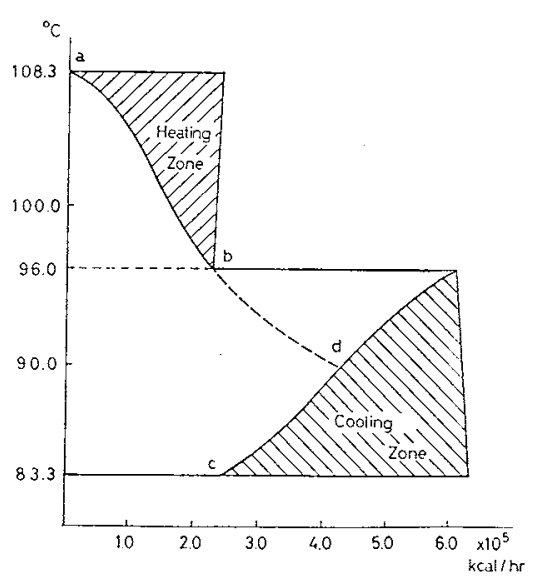

Fig. $9 T-Q$ diagram of Example No. 2

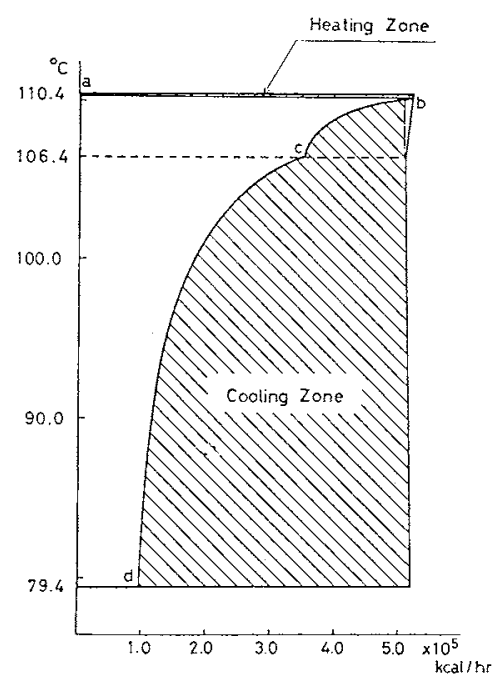

Fig. $10 T-Q$ diagram of Example No. 3

stripping section is evaluated using Eq. (52). Each of the points $a, b, c$ and $d$ are located in the McCabeThiele diagram of Fig. 12. If heat energy more than $\Delta Q_{c(k)}$ is removed from the plate on the bc curve, it is necessary to supply heat energy in the cd section. 


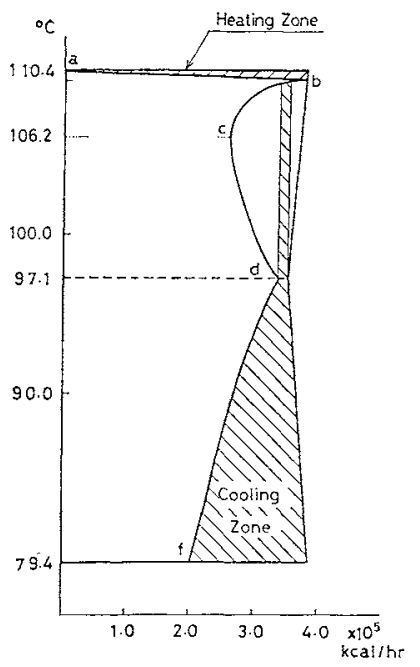

Fig. $11 T-Q$ diagram of Example No. 4

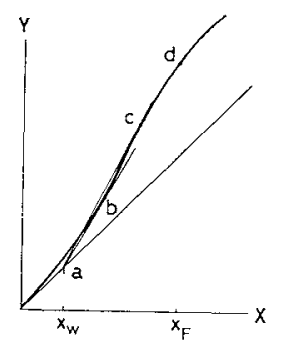

Fig. $12 x-y$ diagram of Example No. 4

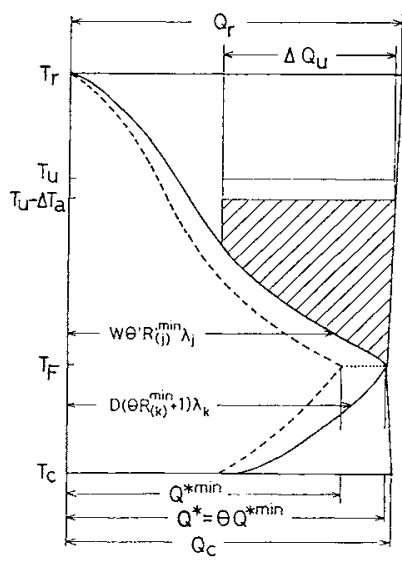

Fig. $13 T-Q$ diagram of a distillation column with reflex ratio, $\theta R^{\mathrm{min}}$

\section{The Effective Arrangement of Side-Boilers and Side-Coolers}

In general, it is assumed that the reflux ratio, $R$, is equal to $\theta R^{\mathrm{min}}(\theta>1)$ for the short-cut design method of a distillation column. If this assumption is satisfied in the design of a column with side-boilers and coolers, Eqs. (37) and (45) change to the following equations:

$$
\begin{aligned}
& Q_{c(k)}=D\left(\theta R_{(k)}^{\min }+1\right) \lambda_{k}+Q_{(k)}^{+} \\
& Q_{r(j)}=W \theta^{\prime} R_{(j)}^{\min _{j} \lambda_{j}}+Q_{(j)}^{-}
\end{aligned}
$$

where

$$
\theta^{\prime}=\left\{D \theta R_{(f)}^{\min }+(1-q) F\right\} / W R_{(f)}^{\min _{(j)}}
$$

The total supplied and removed heat energies can be derived as follows.

(i) If the pinch point for the minimum reflux ratio is in the stripping section or at the feed plate,

$$
\begin{aligned}
& Q_{r}=W \theta^{\prime} R^{\prime \min } \lambda_{p}+Q_{(p)}^{+} \\
& Q_{c}=Q_{r}-Q_{F}^{-}+Q_{F}^{+}
\end{aligned}
$$

(ii) If the pinch point for the minimum reflux ratio is in the enriching section,

$$
\begin{gathered}
Q_{c}=D\left(\theta R^{\mathrm{min}}+1\right) \lambda_{p}+Q_{(p)}^{+} \\
Q_{r}=Q_{c}+Q_{F}^{-}-Q_{F}^{+}
\end{gathered}
$$

Set $\theta=1.2$ for example No. $1, Q_{c(k)}$ and $Q_{r(j)}$ are shown in Fig. 13.

When a utility with $T_{u}$ temperature and $Q_{u}$ heat energy is near a distillation column, the feasible domains of temperature and heat energy can be easily obtained in order to use it. If the utility satisfies the following condition, it is possible to add a side-boiler.

$$
\bar{T} \geqq T_{u}-\Delta T_{a} \geqq T_{j}
$$

where $\Delta T_{a}$ means the minimum approach temperature difference. Then the useful heat energy, $\Delta Q_{u}$, is calculated as follows:

$$
\begin{gathered}
\text { if } \Delta Q_{r(j)} \geqq Q_{u}, \Delta Q_{u} \leqq Q_{u} \\
\text { or if } \Delta Q_{r(j)}<Q_{u}, \Delta Q_{u} \leqq \Delta Q_{r(j)}
\end{gathered}
$$

\section{Conclusion}

In this paper, when there are several utilities around a distillation system, the method of using the energy sources is considered. By calculating the limiting curves of heating and cooling from the specifications of feed and products, vapor-liquid equilibrium and the pinch point conditions, it is easy to find the feasible domains for side-boilers and side-coolers and the relationship between the heat energy and the temperature of such a heat exchanger. Moreover, this method is a very powerful means of solving the design problems of a heat pump and the synthesis of a heatintegrated distillation system. The application of this method to these problems will be considered.

Appendix: The limiting temperature of using a side-boiler, $\underline{T}$ or a side-cooler, $\bar{T}$

At first, consider the limiting temperature of using a sideboiler. $T_{p}$ means the temperature of the pinch point with minimum reflux, $T_{\mathrm{c}}<T_{p}<T_{F}$. At the pinch point temperature, $T_{k}$, in $T_{p}<T_{k}<T_{k}$, the heat energy removed from a condenser, $Q_{c(k),}^{\min }$, is required using Eq. (33):

$$
Q_{o(k)}^{\min }=D\left(R_{(k)}^{\min }+1\right) \lambda_{k}+Q_{(k)}^{+}
$$

and the minimum total removed heat energy is given by Eq. (36):

$$
Q_{c(k)}^{\min }=Q^{* \min }+Q_{F}^{+}
$$

Under constant $Q_{c}^{\min }$, if the region with $Q_{c}^{\min }-Q_{c(k)}^{\min }>0$ is in $T_{p}<T_{k}<T_{F}$, operation using a side-boiler is feasible. 


$$
\begin{aligned}
\Delta Q_{r(k)}= & Q^{\min }-Q_{c}^{\min } \\
= & Q^{* \min }-D\left(R_{(k)}^{\min }+1\right) \lambda_{k}+F(1-q) \lambda_{F} \\
& +D\left\{c_{F}\left(T_{F}-T_{\circ}\right)-c_{k}\left(T_{k}-T_{\circ}\right)\right\}
\end{aligned}
$$

The third and the fourth terms in the foregoing equation mean heat sources except for side-boiler and a reboiler. Consequently, the heat energy supplied to a side-boiler at the $j$-th plate is

$$
\Delta Q_{r(k)}=Q^{* \min }-D\left(R_{(k)}^{\min }+1\right) \lambda_{k}
$$

The temperature to satisfy $\Delta Q_{r\langle k\rangle}=0$ is defined as "the limiting temperature of using a side-boiler", $\underline{T}$. Though there is a limiting curve of cooling in $T_{p}<T_{k}<T_{F}$, it has to be neglected under the constant heat duty. Similarly, the limiting temperature of using a side-cooler, $T$, has to be defined.

$$
\Delta Q_{e(j)}=Q^{* \min }-W R_{(j)}^{\prime \min } \lambda_{j}=0
$$

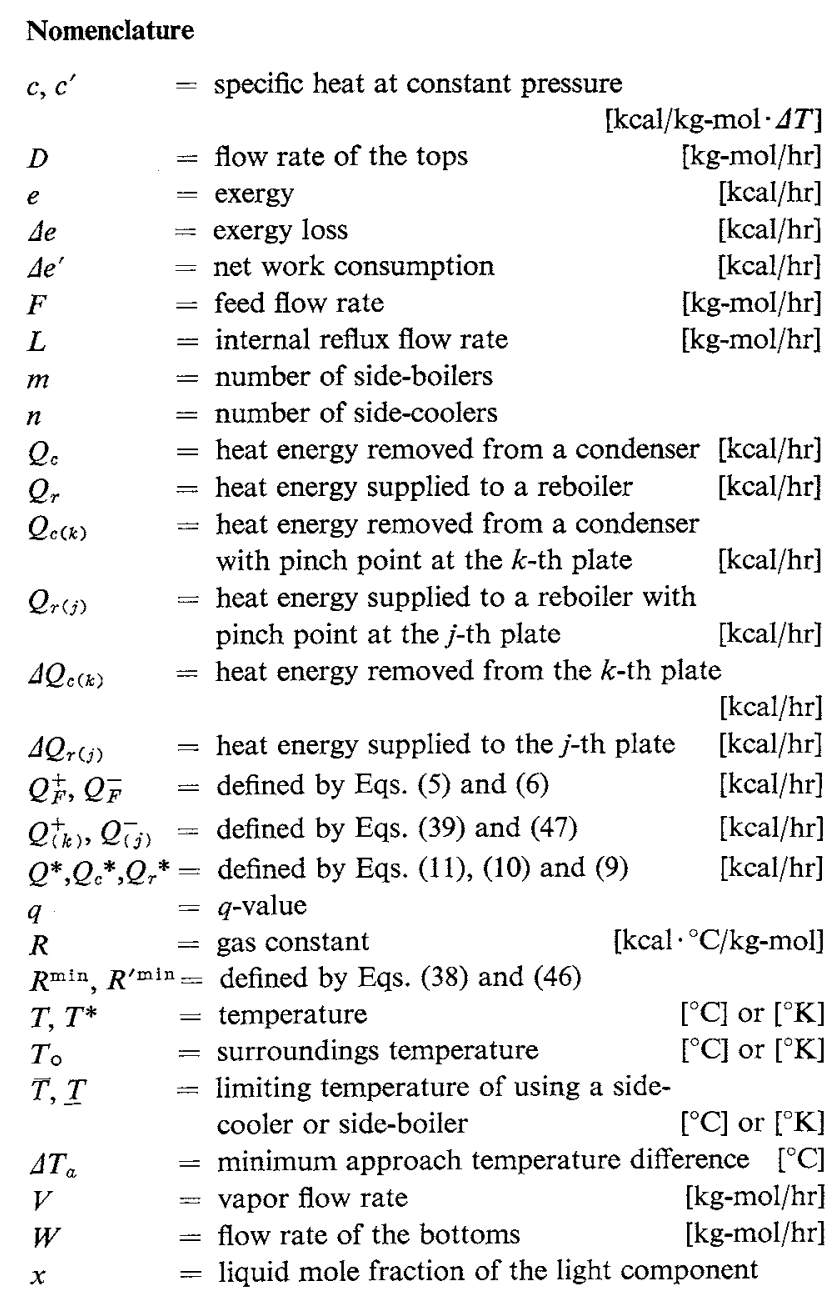

$$
\begin{array}{llr}
y & =\text { vapor mole fraction the light component } \\
\pi & =\text { operating pressure } & {[\mathrm{mmHg}]} \\
\lambda & =\text { latent heat } & {[\mathrm{kcal} / \mathrm{ky}-\mathrm{mol}]} \\
\omega & =\text { work supplied to a pump } & {[\mathrm{kcal} / \mathrm{hr}]}
\end{array}
$$

$\langle$ Superscript $\rangle$

$$
\min \quad=\text { pinch point }
$$

〈Subscripts〉

$$
\begin{array}{ll}
c & =\text { condenser or side-cooler } \\
d & =\text { the tops } \\
F & =\text { feed } \\
f & =\text { feed plate } \\
j, k & =\text { plate number } \\
p & =\text { the pinch point corresponding to minimum } \\
& \quad \text { reflux ratio } \\
r & =\text { reboiler or side-boiler } \\
u & =\text { utility } \\
w & =\text { the bottoms }
\end{array}
$$

\section{Literature Cited}

1) Eguchi, W.: "Kagakukōgakuryōron", Kagakudōjin, Tokyo (1975).

2) Hamaoka, S.: '75 International Chemical Plant Engineering Congress, Preprint-Distillation, Tokyo (1975).

3) Harima, M.: Chemical Engineering (Japan), 21, (6), 22 (1976).

4) Hirata, M., S. Ohe and K. Nagahama: "Vapor-liquid Equilibrium Data", Kodansha, Tokyo (1975).

5) Itoh, J., K. Niida, K. Shiroko and T. Umeda: Kagaku Kogaku Ronbunshu, 5, 1 (1979).

6) Kayihan F.: 70th AIChE Meeting, Nov. (1977).

7) Kawahigashi, J.: "Jōryū Neturikigaku", Tokyo-tosho, Tokyo (1970).

8) King, C. J.: "Separation Processes", McGraw-Hill, New York (1971).

9) Linnhoff, B., and R. Smith: Distillation Symposium Proceeding, London (1979).

10) Null, H. R.: "Process Design for Energy Conservation", AIChE Today Series, Sec. 7., New York (1976).

11) Petterson, W. C. and T. A. Wells: Chem. Eng., 26, (9), 78 (1977).

12) Robinson, C. S. and E. A. Gilliland: "Elements of Fractional Distillation", 4th ed., McGraw-Hill, New York (1950).

13) Timmer, Jr., A. C.: Distillation Symposium Proceeding, Brighton (1969).

14) Tyreus, B. D., and W. L. Luyben: Hydrocarbon Process., 54, (7), 93 (1975). 